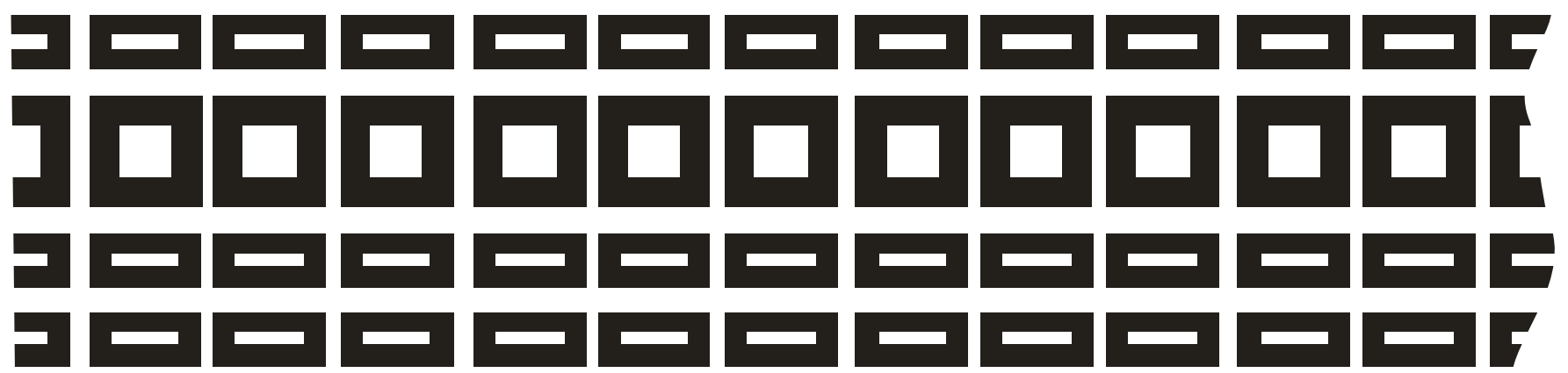

\title{
O Espaço da Transculturação
}

\author{
Elaine de Almeida
}

\section{Resumo}

O presente trabalho tem o propósito de estudar o processo de transculturação ocorrido entre Europa e América Latina, desde os tempos da colonização da América Latina até os nossos dias, nos campos político, histórico e social e suas repercussões na literatura e no pensamento latino-americano contemporâneo, à luz dos estudos de Ángel Rama, no livro A Cidade das Letras (1985).

Palavras-chave: Transculturação; colonização; língua; literatura; cidades.

\section{Abstract}

This proposal of this assignment is the analysis of Transculturation process occurred between Europe and Latin America, since the Latin America settlement until the present days, in the politics, historic and social fields and their repercussion in the literature and in the Latin American contemporary musing, considering Ángel Rama studies presented in the book A Cidade das Letras (1985).

Keywords: Transculturation; settlement; language; literature; cities. 
Desde os primórdios, o Homem se vê em contato com culturas alheias à sua, seja no papel de dominante ou de dominado. O choque cultural e a consequente sobreposição, e até mesmo a substituição de uma cultura pela outra; são resultados da dominação político-econômica de uma nação ou império sobre outros povos, em terras ainda não conhecidas pelo então conquistador. E, pensando num nível mais atual, tal domínio ocorre de um país desenvolvido sobre países em desenvolvimento, através da intervenção do comércio e da mídia, transmissora de costumes e tradições estrangeiras como modelo cultural e padrão de vida ideal.

Em meio ao cenário das colonizações espanhola e portuguesa na América, o europeu invasor impôs sua língua, religião e costumes aos povos indígenas do Novo Continente, num processo de barbárie e contínua violência, tanto no nível físico quanto no cultural e social. A esse processo de contato, presente no jogo da dominação, imposto, sobretudo, pelo empreendimento colonial, o antropólogo Fernando Ortiz dá o nome de transculturação (termo proposto em 1940). A aplicação desse conceito será a base do escritor uruguaio Ángel Rama, em sua reflexão teórica acerca da literatura latino-americana.

Esse processo se daria em três momentos: a desculturação, onde há a perda dos componentes culturais do povo dominado; logo, a incorporação de uma cultura externa imposta e, por fim, uma neoculturação, ou seja, a articulação dos elementos culturais originais junto aos externos adquiridos.

Posteriormente, nas obras literárias, o processo transculturador também se daria em três níveis: o linguístico, onde pode haver o resgate da linguagem regional e o consequente confronto entre o culto e o popular; a estruturação, momento em que a cultura dominada busca construir mecanismos literários próprios - no Brasil, o índio, o negro e o mestiço são apresentados diferenciadamente da literatura hispânica, como por exemplo, em Macunaíma, de Mário de Andrade; por último, a cosmovisão, onde se reiteram ideologias e se criam novos signos.

O romance, para Rama, foi o gênero que funcionou como peça chave na formação da literatura latino-americana, pois surgiu de uma nova sociedade, sendo consequência dessa transformação e representando uma subversão aos modelos vigentes. Além disso, essa forma literária ganha autonomia e grande poder linguístico, recuperando características populares, sem cair no caricato. A literatura latino-americana, quando emergente, explicita criatividade e adquire dimensão cultural ao propor uma dialética entre a busca da universalidade e a manifestação da particularidade, visto que, à influência europeia, se uniam elementos tradicionais locais.

A Europa, considerada modelo de vanguarda, mais do que somente uma referência, é a "forma" onde se ajusta a literatura hispano-americana; esta, porém, graças a Guimarães Rosa, José Maria Arguedas, Roa Bastos, só para citar alguns, consolida o resultado positivo da transculturação, elevando a literatura latino-americana contemporânea tanto a um autorreferencial, como a um referencial mundial.

Para entendermos o processos transculturador, no âmbito colonial espanhol na América, é preciso recorrermos aos processo históricos de formação das cidades americanas, que serão tanto o palco das transformações socioculturais, como também o cenário para o desenvolvimento e afirmação política, histórica e cultural da literatura latinoamericana, como nos apresenta Ángel Rama no livro A Cidade das Letras (São Paulo: Brasiliense, 1985). 
Desse modo, é imprescindível falarmos da formação das cidades e do povo colonizado e, posteriormente, sobre as manifestações artísticas surgidas na América e o processo de construção das mesmas, levando em conta a influência do colonizador sobre elas e como se desenvolve a questão da identidade latino-americana diante desse confronto.

A cidade latino-americana é resultado do projeto de uma ordem sonhada pelos conquistadores; ordem essa, somente possível nas terras virgens do Novo e vasto continente. Ao longo do séc. XVI, os próprios conquistadores perceberam que aquele modelo de cidade em nada mais lembrava a cidade orgânica "medieval". Era uma nova concepção de espaço, uma nova maneira de distribuição, adaptada àquele também novo modo de vida. Os conquistadores perceberam que não somente cruzaram o Atlântico, mas também ultrapassaram as barreiras do tempo, rumo a um novo pensamento, permitindo assim a expansão de sua economia mercantilista, mesmo ainda imbuídos do caráter missionário medieval. Desse modo, a América, em vez de folha em branco para simples colagem do modelo europeu de cidades, foi palco da materialização do sonho de uma nova época.

Antes de ser uma realidade de ruas e edificações urbanas no processo histórico e temporal, as cidades nasciam num processo, denominado por Ángel Rama de "parto de inteligência". Ou seja, surgiam de um processo racional: os colonizadores as projetavam, segundo normas sociais e planos arquitetônicos. Esse processo se deu através da transmissão de signos, baseados numa razão ordenadora, repassada desde a mente do colonizador até o espaço físico da terra conquistada; era uma ordem social imaginada tornando-se realidade.

O que houve, porém, não foi a transposição pura e simples de um modelo de sociedade europeu, mas a sua organização é transposta e adaptada ao espaço físico encontrado. Posteriormente, essa mesma ordem implicará a busca de uma identidade latino-americana mediante à ideologia implantada pelo poder, para legitimar-se. Ou seja, a imposição da ideologia do poder conquistador resultará na formação de ideologias substitutas no pensamento do povo conquistado, para subverter a ordem estabelecida e para reclamar sua própria autonomia.

Para registrar a posse da nova terra foi necessária a intervenção da palavra escrita: o documento de posse legitimava o que era apenas falado, suposto, subentendido; o ato de escrever era o ato de dar fé, ou seja, a escrita surge na América Latina, a princípio, como a única garantia válida e segura, que solidificava o domínio da Corte, expressando-o ao nível cultural. Tal registro é um marco ideológico e insere a América no espaço do real, garantindo sua permanência, visto que ao registrarmos algo, conseguimos sua perpetuidade, ainda que o objeto registrado já não exista.

A América Latina passa a existir a partir daí, mas somente sob o rótulo de colônia na visão dos colonizadores. Na verdade, a grande luta do povo latino-americano, desde então, é exatamente provar que existe, é buscar e consolidar sua identidade.

As cidades filhas da conquista, no entanto, não vieram somente para exercer o efêmero papel de feitorias, mas sim o de cidades permanentes, num gradativo processo de colonização. E para construir ali uma sociedade civilizada, segundo Domingo Faustino Sarmiento (RAMA, 1985) era preciso o desenvolvimento de uma educação letrada, transformando assim, o território, antes selvagem, numa cidade civilizada. Pensamento e teoria que se concretizaram historicamente, mas num âmbito muito mais agressivo e 
violento, como o que ocorreu em Canudos e retratado, por Euclides da Cunha, em Os Sertões.

Após o primeiro momento de barbárie, o processo colonizador, com seu caráter dominador e repressivo, consistiu ainda em evangelizar e educar o povo nativo para, assim, ainda mais subjugá-lo à soberania imperial. Ambos aspectos - religioso e agnóstico - componentes do processo de transculturação, segundo modelo europeu.

Dados esses dois modos de "civilizar", durante muito tempo, ambos setores estiveram unidos, o intelectual e o eclesiástico, para melhor impor a hierarquização social e consolidar o poder do sistema monárquico. Cultura e religião, portanto, continuam lado a lado em busca do estabelecimento da ordem europeia na nova terra, sendo a catequese um dos exemplos dessa fusão.

Cerca de dois séculos depois, os jovens ricos da nova terra eram salvos do "perigo" da ociosidade e levados ao caminho do bem através das letras, também pela mão dos jesuítas. Esta é a cidade denominada letrada, por Ángel Rama, na qual a palavra era instrumento a serviço da dominação e, a educação, com seu caráter sacerdotal, corroborava com esse sistema.

Aquele restrito grupo de letrados era o elo de comunicação entre metrópole e colônia, gozando de privilegiado lugar diante da Corte e de todos os benefícios concedidos à esta, através do sistema colonial. Essa elite pôde usufruir de privilégios sustentados pela apropriação das riquezas americanas, que além de favorecer as condições de vida da elite intelectual, também pôde financiar a pompa e a magnitude das igrejas e conventos barrocos. Nesse contexto, podemos observar o cenário controverso, composto pela minoria opulenta de um lado e a maioria miserável de outro.

Esse período, contudo, sofre de escassez na prática da escrita, não por contar com poucos adeptos à produção artística, mas pelo espírito colonizado, resultado do processo catequizador que, provavelmente, podava a capacidade de criação, pois, afinal, as manifestações artísticas surgidas nessa época existem para uso político.

O exercício da letra, portanto, esteve tanto no âmbito político, quanto no religioso e no comercial, contribuindo para as instituições estabelecidas, sendo simultaneamente servidor do poder e também parte desse processo institucionalizador, do qual também se valia. Segundo Ángel Rama, a cidade letrada pouco a pouco se fortaleceu graças à administração colonial e à imposição da evangelização - transculturação - da população indígena.

A cidade letrada articulou sua relação com o poder e quis fixar-se e perpetuarse, e é, nesse sentido, oposta à cidade real, que se modifica e se adapta ao longo da história, tal como muda a sociedade. A cidade letrada simboliza, interpreta e ordena o que a cidade real mostra; e somente essa interlocução é capaz de gerar a projeção de uma cidade ideal, subvertendo a ordem preestabelecida e reconstruindo caminhos para uma nova formação de ideias. Embora a cidade letrada tenha surgido de elementos civilizatórios, só ela pode representar a cidade real, aquela física e sólida. Ambas são interdependentes e complementares.

Devido ao seu constante diálogo com o jogo do poder entre metrópole e colônia, a parcela social letrada favorece um novo comportamento linguístico que, tal como ocorreu com o latim, gerou duas línguas: uma pública, cerimonial e formal, usada no campo religioso e civil e que se registrou na escrita. Outra, cotidiana e coloquial, própria do ambiente privado e relações sociais, com poucos registros. Era o culto versus 
o popular, o que podia ser escrito, imposto como modelo e norma, diante do informal, considerado ignorante e bárbaro.

A língua na América, então, assume seu papel marginalizante e segregador, denominando classes e posições sociais, distinguindo os membros da classe letrada daqueles que ainda não haviam alcançado tal nível. A língua definiu uma "hierarquia social", num ambiente em que a norma culta era a língua do colonizador, a peninsular, o centro da dominação. Tal como profetiza Antonio de Nebrija, na Gramática Sobre a Língua Castelhana, de 1492, "a língua é companheira do império". Portanto, defendê-la seria a função dos letrados a favor de um paradigma do falar correto e da manutenção do poder da metrópole sobre a colônia.

O desaparecimento de "vosotros" e sua substituição por "ustedes" na América hispânica, por exemplo, é prova da atitude defensiva desse continente, preferindo uma língua que the atende e não aquela que lhe é imposta, embora a conjugação da segunda pessoa do plural ainda seja ensinada nas escolas, mesmo não utilizada cotidianamente, permanecendo restrita a uma linguagem artificial.

Com o exercício e reiteração da letra nas cidades americanas, instalaram-se os novos intelectuais, os universitários e os doutores, título almejado por fazendeiros ricos e comerciantes imigrantes para o futuro de seus filhos. Os universitários, seguindo o modelo originado com o advento da classe dos letrados, aceitavam o mundo como lhes era apresentado, não tendo a pretensão de representar a realidade em seus escritos, se não fantasiá-la e idealizá-la.

Tal classe, própria dos núcleos urbanos, dividiu-se, de maneira gradual, basicamente em três setores: a educação, o jornalismo e a diplomacia. A visão idealizada desses profissionais permitiu o crescimento da cidade modernizada (denominação de Ángel Rama), ambiente em que se tornaram "mitos sociais", como menciona o mesmo autor em A Cidade das Letras, por transmitir a ideia de que a letra impunha respeito e era degrau para ascensão social.

Posteriormente, em meio ao setor acadêmico, surgiram as profissões chamadas "liberais", menos relacionadas com o poder e, por isso, imbuídas de um espírito crítico, antes inviável, ainda que também ambicionando os benefícios que o poder poderia fornecer, como aquisição de direitos e bens.

O setor acadêmico latino-americano advém do modelo acadêmico espanhol e, por consequência, recebe influências das doutrinas externas, mas naturalmente vê a necessidade de adaptar o modelo europeu às demandas do comportamento intelectual interno. Embora pouco eficiente e num progresso lento, a aparição dessas academias foi resposta dos letrados à ameaça de subversão, que poderia surgir do desejo de democracia, da liberdade de expressão, agravada pela imigração, outra influência linguística. Em busca de uma modernização, a cidade letrada procurou extinguir traços da cultura rural e a influência do conceito de Natureza, pretendendo ajustar o território nacional, antes selvagem, sob uma ótica puramente urbana.

Por outro lado, com o surgimento e afirmação da literatura na América Latina, o conservantismo e a nacionalidade voltaram a ser marcantes na arte da escrita; nesse novo espaço, reorganizado pelo romanticismo, fortaleceu-se a concepção nacional, diante das produções orais rurais; na literatura, o ingrediente popular foi recurso importante para o fortalecimento da cultura ambientada fora da cidade letrada e distante do ranço dos meios acadêmicos de então. Recuperou-se a colônia como berço, revisitando- 
se o regionalismo e as tradições populares, enquanto a cidade letrada buscava manter-se alheia e oposta a essas manifestações, impondo a escrita como superior à oralidade.

Em meio a esse processo, a equipe intelectual se expande e os escritores se veem com a função ideologizante da escrita. Paralela a isso, a massa inculta, marginalizada - os camponeses, índios e mestiços - que antes via, nos sacerdotes, defensores e mestres, fundindo educação e fé, se insere no setor urbano, cada vez mais em crescimento e tendo que absorver a população periférica. Nesse contexto, a equipe intelectual já não é formada somente pelos descendentes de "boas famílias", mas também de filhos de artesãos, pequenos comerciantes e, até mesmo, filhos de escravos. O fenômeno tranculturador ocorre então, não só através do intercâmbio metrópole-colônia, como também no espaço entre as regióes periféricas e o interior, processo ainda mais lento e gradual, porém, não menos eficaz e pertinente.

Enquanto a antiga elite letrada teve contato direto com o mecanismo do poder, constituiu-se um pensamento crítico opositor, sobretudo no início do século latinoamericano que, ao contrário de atender aos mais fortes, preferiu descrever seus ideais, dotado de uma escrita espiritual e emocional, também capaz de um diálogo político, confrontando-se com o artificialismo literário vigente.

Como nos elucida Néstor García Canclini, em Culturas Híbridas: estratégias para entrar e sair da Modernidade (São Paulo: EDUSP, 2003), houve uma luta pela modernização, um movimento para construir, de maneira crítica, uma nação oposta ao pensamento oligárquico. E, para isso, o movimento modernista latino-americano pretendeu unir todos os setores, aproximando o culto, apropriando-se dos bens históricos - como os centros históricos e a música clássica - e os elementos e tradições populares, sob o nome de "folclore". O patrimônio representa a sobrevivência de uma ideologia e preservá-lo é preservar também modelos estéticos e simbólicos que caracterizam nosso passado histórico e identidade cultural nacional, pois "sem as acumulações da memória, não temos cultura" (JOZEF, 1996).

Sob o intuito da valorização desse passado histórico, o tradicionalismo seria um recurso para suportar as contradições contemporâneas, pois se a modernidade já não atende aos apelos sociais vigentes, a tendência é buscar-se um passado, teoricamente mais tolerável.

Logo, a cidade moderna está para os vanguardistas, assim como a natureza está para os românticos. A América Latina recorreu ao contato com sua natureza, aos seus elementos tradicionais, inclusive rurais e regionalistas porque o modelo vanguardista europeu não lhe atendia de todo e se fez necessária a busca de uma identidade própria. A primeira fase do modernismo latino-americano foi produzida por artistas que voltavam de vivências na Europa, mas não imitaram simploriamente o modelo importado, ao contrário, adaptava-o à realidade latino-americana vigente.

Diante do paralelo entre inovação e costumes, modernidade e tradição, uma mensagem interclassista gerou um interessante choque cultural, que permitia a relação, em um mesmo ambiente burguês, entre o antigo e o recente, num misto de conservação da tradição e o avanço da tecnologia: bibliotecas poliglotas e artesanato indígena, TV a cabo e parabólicas e móveis coloniais. Afinal, segundo Canclini: 
modernos, quanto saber incorporar a arte e a literatura de vanguarda, assim como os avanços tecnológicos, as matrizes tradicionais de privilégio social e distinção simbólica" (CANCLINI, 2003, p.74).

Diante do processo de transculturação, a América absorveu e assimilou - mesmo não pacificamente - os traços culturais europeus, mas não somente os copiou: em lugar disso, deu-lhe novas cores e formas, atrelando, àqueles traços, sua própria visão e pensamento crítico, seus costumes e tradições sobreviventes. Além disso, ao longo do curso da história e das artes, cada um dos países latino-americanos desenvolveu e caracterizou seu estilo nacional.

A América Latina, forçosamente, foi espaço para recepção e expansão de culturas, mas não se sujeitou a ser mera tábula rasa, onde poderiam ser construídas novas cidades e sociedades sob os restritos moldes colonizadores, ainda que o processo de transculturação tenha ocorrido a custo de sangue e perdas.

Se, politicamente, tivemos e temos que sofrer a influência do poder e ainda estamos sujeitos aos constantes processos de dominação, ao menos artisticamente, não aceitamos ser mero experimento de um novo modo de vida. Se somos fruto da expansão marítima e berço da nova economia imperial, o domínio da letra e a manifestação artística nos permite transcender a condição de colônia, transgredindo e reformulando a ordem para alcançar o progresso, sendo, então, sujeitos e não somente objetos da ação transculturadora. O espaço da transculturação é terreno fértil para se plantarem novas ideias e forças criadoras, mas é preciso estabelecer, ao menos culturalmente, a união saudável entre o original e o novo, o nacional e o estrangeiro, o tradicional e o moderno.

A palavra tem caráter transformador, sendo instrumento de dominação e manipulação, no texto e na voz de quem detém o poder. Mas, fazendo jus ao pensamento de Ángel Rama, que considera o ato da escrita um ato político, é também através da palavra, sobretudo a partir da escrita e do fazer literário, que podemos cogitar a construção de uma América Latina autônoma.

\section{Referências bibliográficas}

CANCLINI, Néstor García. Culturas Híbridas: estratégias para entrar e sair da Modernidade. São Paulo: EDUSP, 2003.

JOZEF, Bella. Literatura e Identidade. Ensaio apresentado na Universidade Federal Fluminense, Rio de Janeiro, em 1996. O espaço reconquistado. Petrópolis: Vozes, 1974.

RAMA, Ángel. A Cidade das Letras. São Paulo: Brasiliense, 1985. Literatura e Cultura na América Latina. São Paulo, EDUSP, 2001. 